\title{
Model Development and Loads Analysis of a Wind Turbine on a Floating Offshore Tension Leg Platform
}

Conference Paper NREL/CP-500-46725

February 2010

Denis Matha, Tim Fischer, Martin Kuhn University of Stuttgart, Germany

Jason Jonkman

National Renewable Energy Laboratory

Presented at the 2009 European Offshore Wind Conference and Exhibition

Stockholm, Sweden

September 14-16, 2009
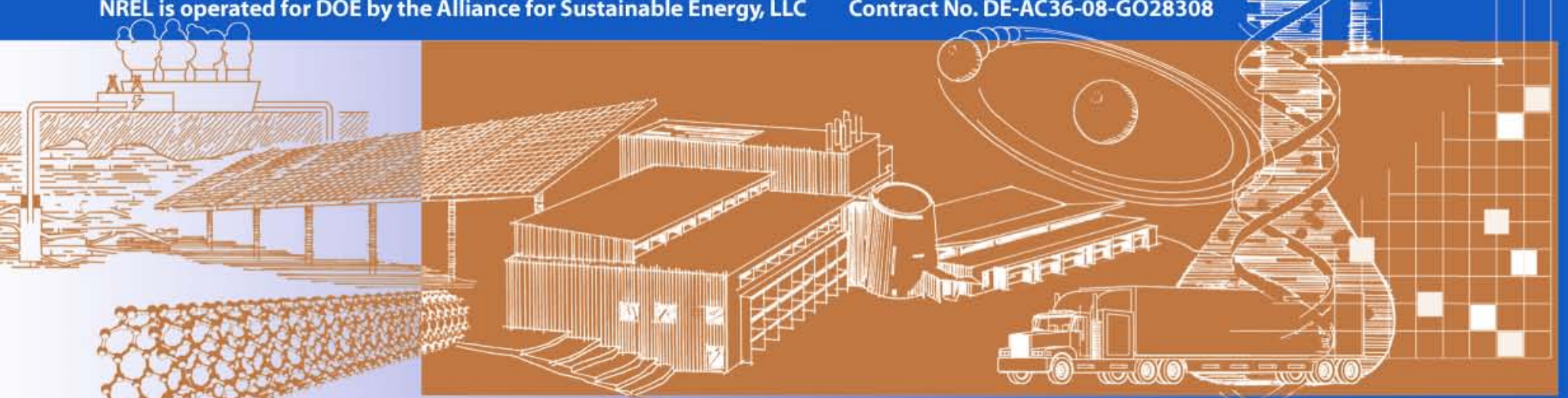


\section{NOTICE}

The submitted manuscript has been offered by an employee of the Alliance for Sustainable Energy, LLC (ASE), a contractor of the US Government under Contract No. DE-AC36-08-GO28308. Accordingly, the US Government and ASE retain a nonexclusive royalty-free license to publish or reproduce the published form of this contribution, or allow others to do so, for US Government purposes.

This report was prepared as an account of work sponsored by an agency of the United States government. Neither the United States government nor any agency thereof, nor any of their employees, makes any warranty, express or implied, or assumes any legal liability or responsibility for the accuracy, completeness, or usefulness of any information, apparatus, product, or process disclosed, or represents that its use would not infringe privately owned rights. Reference herein to any specific commercial product, process, or service by trade name, trademark, manufacturer, or otherwise does not necessarily constitute or imply its endorsement, recommendation, or favoring by the United States government or any agency thereof. The views and opinions of authors expressed herein do not necessarily state or reflect those of the United States government or any agency thereof.

Available electronically at http://www.osti.gov/bridge

Available for a processing fee to U.S. Department of Energy and its contractors, in paper, from:

U.S. Department of Energy

Office of Scientific and Technical Information

P.O. Box 62

Oak Ridge, TN 37831-0062

phone: 865.576.8401

fax: 865.576 .5728

email: mailto:reports@adonis.osti.gov

Available for sale to the public, in paper, from:

U.S. Department of Commerce

National Technical Information Service

5285 Port Royal Road

Springfield, VA 22161

phone: 800.553.6847

fax: 703.605.6900

email: orders@ntis.fedworld.gov

online ordering: http://www.ntis.gov/ordering.htm 


\section{List of Acronyms}

$\begin{array}{ll}\text { BEM } & \text { blade-element / momentum } \\ \text { DEL } & \text { damage-equivalent load } \\ \text { DLC } & \begin{array}{l}\text { design load cases } \\ \text { degree of freedom }\end{array} \\ \text { DOF } & \text { International Electrotechnical Commision } \\ \text { IEC } & \text { low-speed shaft } \\ \text { LSS } & \text { Massachusetts Institute of Technology } \\ \text { MIT } & \text { probability density function } \\ \text { PDF } & \text { response amplitude operator } \\ \text { RAO } & \text { root mean square } \\ \text { RMS } & \text { tension leg platform } \\ \text { TLP } & \end{array}$




\section{Executive Summary}

This report presents results of the analysis of a 5-MW wind turbine located on a floating offshore tension leg platform (TLP) that was conducted using the fully coupled time-domain aero-hydroservo-elastic design code FAST with AeroDyn and HydroDyn. Models in this code are of greater fidelity than most of the models that have been used to analyze floating turbines in the pastwhich have neglected important hydrodynamic and mooring system effects. The report provides a description of the development process of a TLP model, which is a modified version of a Massachusetts Institute of Technology design derived from a parametric linear frequencydomain optimization process. The model has been verified using comparisons to frequencydomain calculations in terms of response amplitude operators and probability density functions. Important differences have been identified between the frequency-domain and time-domain simulations, and have generated implications for the conceptual design process. An extensive loads and stability analysis for ultimate and fatigue loads according to the procedure of the International Electrotechnical Commision 61400-3 offshore wind turbine design standard was performed with the verified TLP model. Response statistics, extreme event tables, fatigue lifetimes, and selected time histories of design-driving extreme events are analyzed and presented. Loads for the wind turbine on the TLP are compared to those of an equivalent landbased turbine in terms of load ratios. Major instabilities for the TLP are identified and described. The stability analysis identified an aerodynamic instability in the platform pitch, platform roll, and tower- and blade-bending modes and a platform-yaw instability. 


\section{Table of Contents}

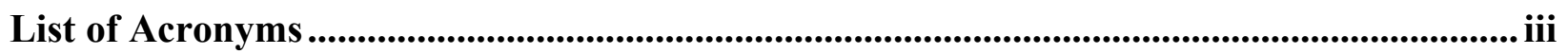

Executive Summary ................................................................................................................... iv

Table of Contents ............................................................................................................................... v

1 Introduction ............................................................................................................................... 1

2 Methods....................................................................................................................... 1

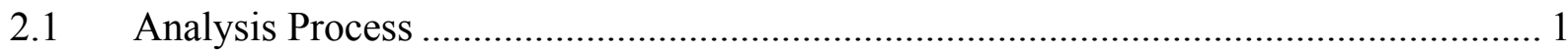

2.1.1 Model Development.................................................................................. 1

2.1.2 Loads and Stability Analysis ………………............................................. 2

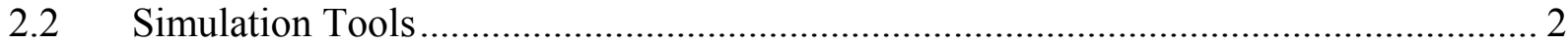

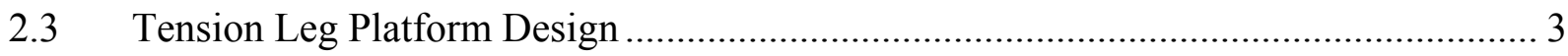



3.1 Time-Domain and Frequency-Domain Comparison ...................................................... 4

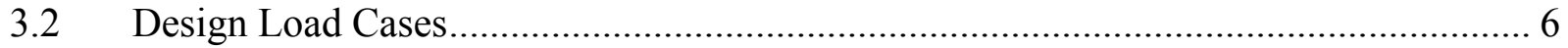

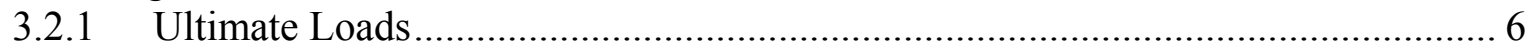

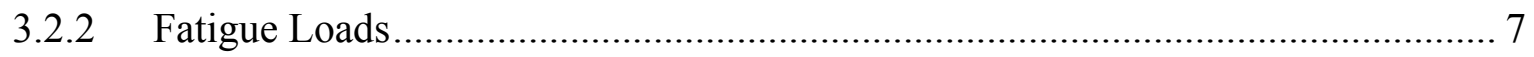

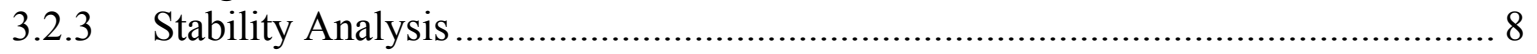

$4 \quad$ Conclusions...................................................................................................................... 9

$5 \quad$ References................................................................................................................................ 10 


\section{Introduction}

The present study aims to provide new insight in the modeling, loads, and dynamics of wind turbines on floating offshore tension leg platforms (TLPs). In the United States, China, Japan, Spain, Norway, and many other countries, shallow-water areas are scarce. Additionally, onshore space requirements and the public pressure to place wind turbines out of visual range further increase the demand for offshore wind turbines in deeper coastal waters. Huge potential sources for supplying coastal areas with offshore wind energy therefore are wind turbines located on floating support platforms in deep offshore waters (in depths of approximately $60 \mathrm{~m}$ to $900 \mathrm{~m}$ ). This provides a huge future market for floating offshore wind turbines. Even at transitional depths of $30 \mathrm{~m}$ to $60 \mathrm{~m}$, floating structures could be a viable alternative to conventional monopile, tripod, and jacket structures.

A requirement for deep-water floating offshore wind turbines is the development of reliable, viable floating-platform support structures. Developing cost-effective, high-performance floating wind turbines with structural and dynamic integrity and reliability requires integrated loads analysis according to the International Electrotechnical Commision (IEC) 61400-3 design standard for offshore wind turbines. Such analysis also is crucial for conceptual design and preliminary analysis. The work presented here describes the model development and loads and stability analysis of one primary floating concept, the TLP.

\section{Methods}

\subsection{Analysis Process}

The overall process for the model development and the loads and stability analysis performed in the present study can be summarized concisely as follows.

\subsubsection{Model Development}

- Define the wind turbine and blades: The NREL 5-MW baseline turbine was selected for this study [1].

- Define the geometry and structural properties of the TLP platform and mooring system: A Massachusetts Institute of Technology (MIT) design [2] was chosen and modified for this study [3] (referred to as MIT/NREL TLP herein).

- Define the wind turbine control system: Modification of the baseline control system was not required for the TLP (See Reference 1 for a definition and details of the control system; see Reference 4 for potential modifications required in some floating wind turbines).

- Define the installation site-specific statistical meteorological (wind) and oceanographic (wave) data: A location in the northern North Sea is selected representing severe environmental conditions (c.f. Reference 5).

- Compute the hydrodynamic frequency-domain properties (hydrodynamic-added-mass and hydrodynamic-damping matrices and wave-excitation force vector) of the TLP with the potential-flow based wave-interaction analysis tool, WAMIT [6]. 
- Compute the tower mode shapes of the combined turbine/platform system with the multibody simulation code MSC.ADAMS (TLP design-specific mode shapes are required in the FAST model to obtain viable simulation results).

- Create the FAST model of the MIT/NREL TLP floating platform and the NREL 5-MW baseline turbine.

- Verify the time-domain FAST model with frequency-domain results in terms of response amplitude operators (RAOs) and probability density functions (PDFs) for MIT's extreme sea state reference-load case [2].

\subsubsection{Loads and Stability Analysis}

- Simulate selected design load cases (DLCs) with the verified TLP model according to the IEC 61400-3 design standard.

- Analyze the DLC statistics, time series, extreme event tables, and fatigue loads.

- Identify the critical DLCs: Investigate causes for extreme loads by study of critical DLC time series.

- Identify and analyze the instabilities.

○ Identify instabilities in time series from DLC simulations.

- Isolate instability-driving wind and wave conditions.

○ Linearize model at identified instability conditions.

- Perform linear stability analysis in terms of damping ratios.

- Analyze the causes for instabilities and identify possible solutions.

- Compare the results to an equivalent land-based system in terms of load ratios.

The model design and analysis process described here is not limited to the TLP, but rather can be applied to almost any floating-platform design.

\subsection{Simulation Tools}

This work uses the design tool FAST with AeroDyn and HydroDyn-developed and verified by Jonkman and Buhl [7,5] at NREL - to create the model of the MIT/NREL TLP floating wind turbine design. FAST accounts for the gravitational loads, the behavior of the control and protection systems, and the structural dynamics of the wind turbine. The latter contribution includes the elasticity of the rotor and tower, along with the elastic coupling between their motions and the motions of the support platform. The aerodynamics are calculated in the FAST module AeroDyn, which uses a state-of-the art blade-element / momentum approach (BEM) with empirical corrections to calculate the rotor aerodynamics.

The FAST module HydroDyn adds the capability of simulating time-domain hydrodynamic effects from linear hydrostatic restoring; added-mass and damping contributions from linear radiation, including free-surface memory effects; incident-wave excitation from linear diffraction; and nonlinear viscous drag, including sea-current loading. The code also includes a nonlinear quasi-static mooring line module. 
These models are of higher fidelity than most models used in the past to analyze floating turbines, which neglected important hydrodynamic and mooring system effects. Additionally, FAST can produce linearized representations of the nonlinear aero-elastic wind turbine model to help identify natural frequencies, damping ratios, and instabilities, and to use for developing control systems. Figure 1 illustrates the various FAST modules and their interfaces. A close link between MATLAB (The Mathworks) and FAST exists, enabling the use of MATLAB's comprehensive embedded analysis functions in user-programmed MATLAB routines as a preprocessor and postprocessor or for control-design purposes. To evaluate raw data from the loads analysis with FAST, the software utility Crunch/MCrunch-developed by Marshall Buhl at NREL [8] - is used.

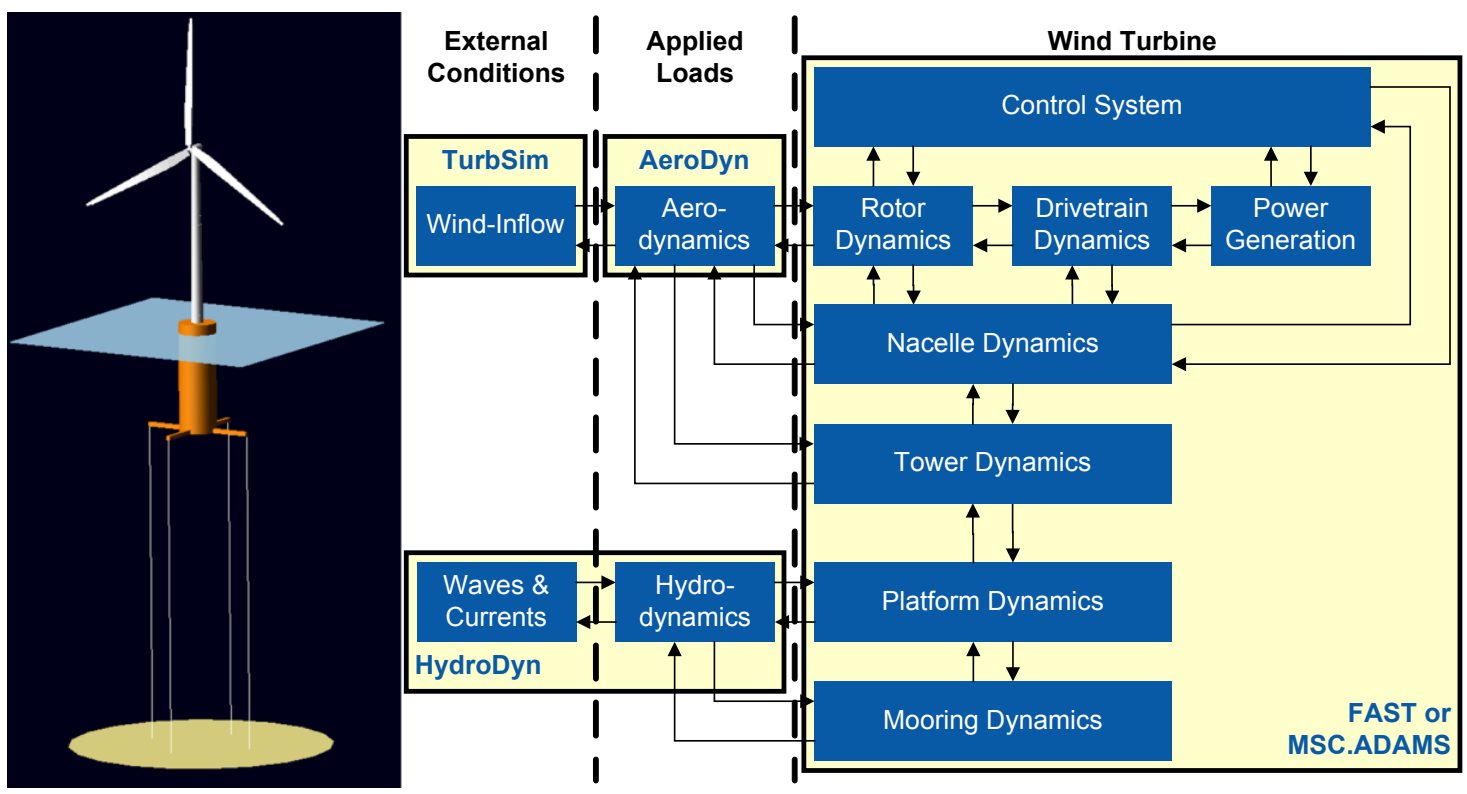

Figure 1. MIT/NREL TLP with FAST, AeroDyn, and HydroDyn modules

\subsection{Tension Leg Platform Design}

As a basis for the development of the FAST TLP model, a TLP design from Tracy's study "Parametric Design of Floating Wind Turbines" [2] (conducted at the MIT Mechanical Engineering Department) was selected. Tracy's thesis contains a parametric optimization study conducted for several different floating-platform concepts for NREL's 5-MW baseline wind turbine. The study resulted in a number of designs that show Pareto fronts for mean-square acceleration of the turbine versus multiple cost drivers, including platform displacement and total mooring-line tension.

Tracy's study concludes that the TLP represents the most attractive choice because of its low root mean square (RMS) accelerations and negligible heave and pitch motions. For the present study, the TLP \#1 for the 10-m reference sea state was chosen. Due to problems with the original design, however, the TLP was modified. The spokes - extending radially away from the TLP cylinder-were lengthened from $9 \mathrm{~m}$ to $18 \mathrm{~m}$; the distance between the connection points for the mooring lines (fairleads) was increased from $36 \mathrm{~m}$ to $54 \mathrm{~m}$. This design change primarily decreased the pitch and roll motions of the platform, thus ensuring the tautness of the mooring lines in the reference sea state. Note that concrete ballast is used to ensure that the combined turbine-platform system remains stable when towing the platform to its installation location in 
mild wind and wave conditions. The TLP design therefore could be much more shallow-drafted and could use much less ballast if the installation process was solved alternatively. The MIT/NREL TLP is shown in Figure 1 and its basic properties are listed in Table 1. Detailed information regarding the modification and TLP design is provided in Matha [3].

\section{Results}

\subsection{Time-Domain and Frequency-Domain Comparison}

To verify the results from the FAST model, a comparison in terms of RAOs and PDFs between time- and frequency-domain simulations was conducted. An RAO represents the nondimensional response of a system to a unit-amplitude periodic incident wave at a given direction. It is the transfer function between the wave amplitude and the platform displacements, depending on the wave frequency and direction. Three different simulations (listed below) are compared to each other, and are presented in Figure 2 for the platform-pitch RAO.

1. Time-domain 22-degree of freedom (DOF) fully flexible model in FAST with AeroDyn and HydroDyn.

2. Time-domain 6-DOF rigid-turbine model in FAST with AeroDyn and HydroDyn, with only the 6 platform DOFs active.

3. Frequency-domain 6-DOF rigid-turbine model in WAMIT, with 6 platform DOFs active.

For the frequency-domain simulation the commercial hydrodynamics code WAMIT was used, but it only accounts for the 6 platform DOFs. WAMIT can directly compute RAOs if the nonhydrodynamic mass, damping, and stiffness matrices of the complete system (i.e., the turbine and platform) about a linearization point are provided as inputs. (For the present study, these linearized matrices were derived from FAST and include the mass, damping, and stiffness matrices associated with turbine weight, rotor aerodynamics, and rotor gyroscopics.) In the chosen reference conditions, the rotor is spinning at rated $12.1 \mathrm{rpm}$ at a constant hub-height wind speed of $11 \mathrm{~m} / \mathrm{s}$ with no shear. 


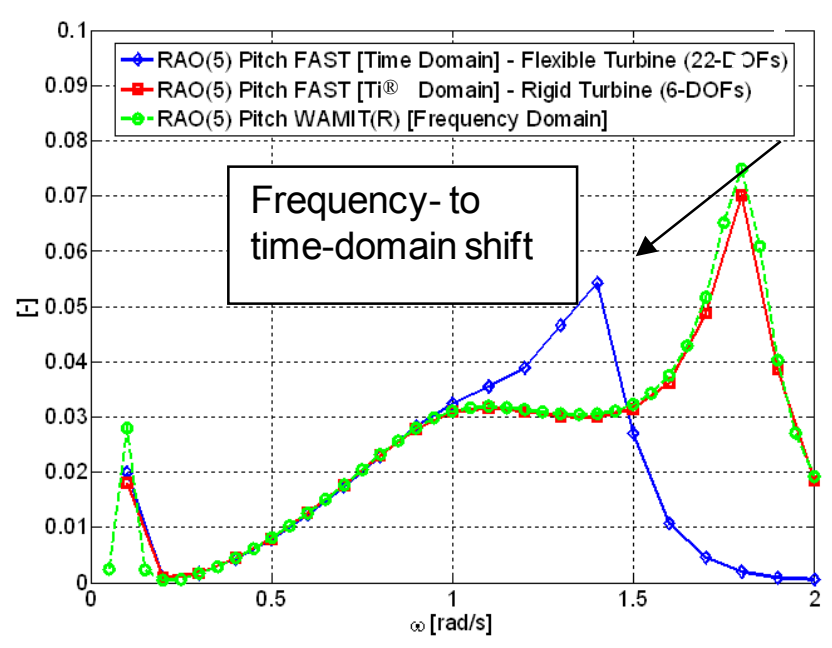

Figure 2. Response amplitude operator comparison for platform pitch

These frequency-domain results are compared with the RAOs and PDFs calculated using FAST in the time domain. In FAST, the RAOs are obtained simply by running numerous simulations with periodic 1-m amplitude waves at different wave periods while the control system is turned off. After the transient effects have disappeared, the amplitudes of the platform's constantamplitude surge, sway, heave, roll, pitch, and yaw displacement oscillations are recorded for each selected wave period. The resulting amplitudes at different wave periods are equivalent to the RAOs for each platform DOF.

To imitate the frequency-domain approach in FAST, and thus validate the model by the comparison to the frequency-domain results, the turbine also is simulated as a completely rigid structure. This approach results in RAOs represented by the red curve shown in Figure 2. These FAST-generated RAOs match the WAMIT RAOs (shown in green) almost perfectly. The agreement of the RAOs thus constitutes a code-by-code verification of the FAST model with the commercial WAMIT code.

The most important differences between the RAOs obtained with the fully flexible FAST model and the WAMIT and rigid FAST models are the lower maxima and the shifting of the peaks towards smaller frequencies. The difference is caused by the missing turbine flexibility in the WAMIT and rigid turbine FAST models: The couplings between platform motions and the flexible tower and blades - which mostly are not captured in a typical frequency-domain approach-have a significant influence on the results. Particularly, the shift of the peaks to smaller frequencies in the time domain could cause problems in a design process that relies on frequency-domain simulations. A design which has no resonance problems in the frequency domain - because all RAO maxima are outside the critical resonance zone - could fail in the time domain. This is because downshifting to smaller frequencies could move these maxima into the critical resonance frequency ranges and cause severe resonance issues. In other simulations, not included here, the tower-bending DOFs were found to have the most significant impact on the shift for this TLP design.

In addition to the deviations in the RAOs, the PDFs also show significant differences between time-domain and frequency-domain simulations (for charts of the PDF comparison, see Matha 
[3]). In surge, heave, and pitch, the time-domain and frequency-domain results are similar. The PDFs have the same means and approximately the same standard deviation. In contrast, the PDFs for the platform's sway, roll, and yaw motions differ considerably. The WAMIT solutions have a much smaller standard deviation and therefore have highly increased peak PDF values, but the means remain the same.

The frequency-domain model is based on a 6-DOF floating-turbine model linearized about a deflected position, based on the thrust and torque from the aerodynamic loads in the referenceload case. The incoming wind and waves - proceeding in downwind direction along the platform's surge direction - primarily excite the pitch, surge, and heave modes and only modestly excite sway, roll, and yaw modes. In the frequency-domain model, the gyroscopic coupling between the rotor and support structure is captured, but the turbine flexibilities are neglected. The PDFs therefore show a very small standard deviation around the mean. The PDFs indicate that, in general, the standard deviations of frequency-domain simulations are much smaller (and the peaks higher) as compared to the time-domain simulations, because nonlinearities are neglected. In future frequency-domain design processes, these findings should be considered carefully. It is suggested that at least one tower fore-aft bending DOF should be added to the frequency-domain model to account for the neglections.

\subsection{Design Load Cases}

Using the FAST TLP model, multiple simulations of selected design load cases from the IEC 61400-3 standard [9] are defined and run. Only a subset of these DLCs is selected for the loads analysis of the TLP. First, DLCs 8.x which define transport, assembly, maintenance, and repair situations are discarded. The baseline control system routine does not include logic for start-up and shutdown events, therefore DLCs 3.x, 4.x, and 5.x-defining start-up, normal shutdown, and emergency shutdown situations - also are omitted. For fatigue analysis only DLC 1.2 is selected. The remaining DLCs simulated in the present study are:

- Power production: 1.1 (1.2), 1.3, 1.4, 1.5, 1.6a;

- Power production and fault: 2.1,2.3;

- Parked: 6.1a, 6.2a, 6.3a; and

- Parked and fault: 7.1a.

\subsubsection{Ultimate Loads}

Figure 3 compares various output parameter extremes from the TLP and the land-based turbine ratios for DLCs 1.1, 1.3, 1.4, and 1.5. The bar chart presents the ratios of the TLP extreme loads divided by the land-based extreme loads. A ratio of 1 , for example, implies that the loads are unchanged compared to the land-based system, and a ratio that is greater or less than unity indicates that the loads have increased or decreased.

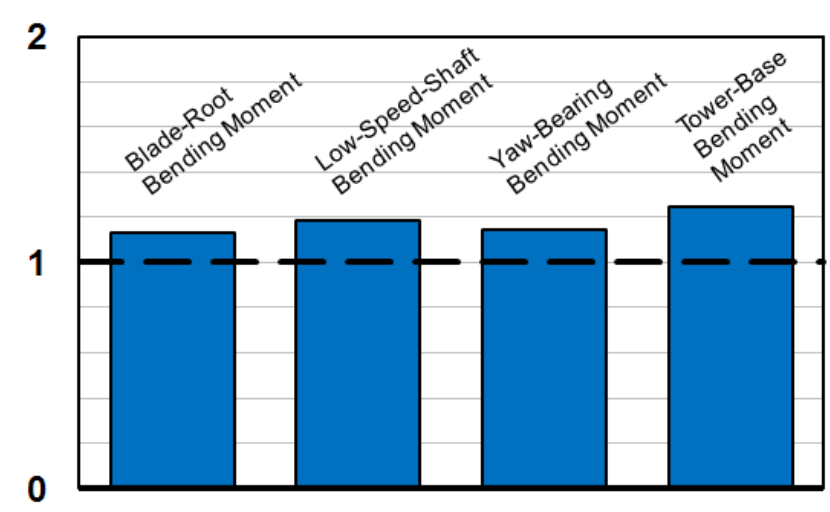

Figure 3. Ultimate load ratios for DLCs 1.1. 1.3. 1.4. 1.5 
Platform translations and rotations resulting in changed inflow increase the combined flap and edgewise blade-root bending moment by $13 \%$. The total low-speed-shaft (LSS) bending moment is increased by $19 \%$. These ultimate loads for blades and LSS occur in DLC 1.4, generated by the extreme coherent gust with direction changes. The total tower-top yaw bearing moment is $14 \%$ greater than for the land-based system. The most significant increase of $25 \%$ occurs in the tower-base bending moment. The main causes of these increased loads are the comparatively large surge and pitch motions (displacements and accelerations) due to platform-wave interaction in DLC 1.1.

These load ratios provide a basis to estimate the impact on structural loads of placing a wind turbine on a floating TLP in an offshore environment. Based on this data, necessary changes to the land-based turbine design — such as strengthening of the tower base - can be estimated. These results make possible a detailed cost analysis, however it is out of the scope of this work. A more detailed analysis of the TLP's ultimate loads, including time series and statistics analysis, is presented in Matha [3].

\subsubsection{Fatigue Loads}

The fatigue calculations in this analysis were performed according to the procedure described in Matha [3]. The damage-equivalent loads (DELs) were calculated according to equation 1, in which $L_{k}^{R F}$ is the k-th load range transformed to a fixed mean (i.e., the load means are taken into account), $n_{j k}^{\text {Liff }}$ is the number of lifetime cycles in the k-th load-range bin and j-th wind-speed bin, $m$ represents the $\mathrm{S} / \mathrm{N}$ slope, and $n_{j}^{\text {Lije,eq }}$ in the denominator is the number of equivalent lifetime cycles in the $\mathrm{j}$-th wind-speed bin. A detailed description of equation 1 and the fatigue-analysis process used in this study are provided in Matha [3].

$$
D E L^{L i j e}=\left[\frac{\sum_{j} \sum_{k} n_{j k}^{L j e}\left(L_{k}^{R F}\right)^{m}}{\sum_{j} n_{j}^{L i j e, e q}}\right]^{\frac{1}{m}}
$$

Figure 4 presents fatigue DEL ratios for DLC 1.2 for three different $\mathrm{S} / \mathrm{N}$ slopes $m$. Ratios greater than one represent a higher DEL, meaning that the floating machine's lifetime is less than that of

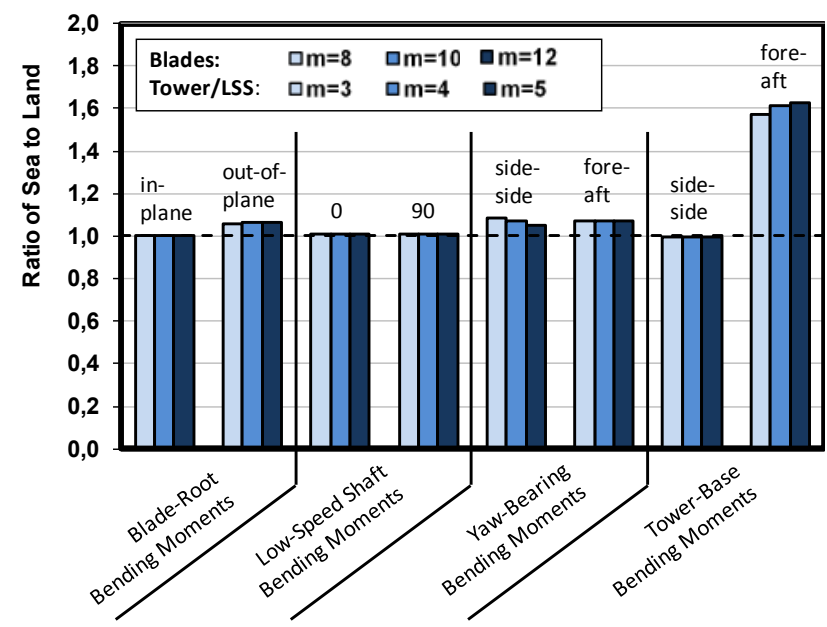

Figure 4. Fatigue load ratios for DLC 1.2 the land-based unit. The blade-root bending moment ratio in-plane remains nearly unchanged. The flap-wise moment ratios are increased because the greater pitch motion of the TLP influences the flap-wise blade-root moments and decreases the fatigue life of the blades. Ratios for the low-speed-shaft bending moments show only slight increases. This is due to the fact that both the TLP and the landbased turbine use the same control system and platform motions have negligible effects on the LSS. The tower-top yaw bearing moments show increased DELs, which are caused by wave-induced platform motions in pitch, surge, and roll. For the side-to-side and fore- 
aft tower-base bending moment ratios, the greatest increase occurs for the fore-aft momentwith ratios increased as much as $60 \%$. The increased pitch motion is the driving mechanism here, because it has its greatest effect on the tower-base bending moment due to the large tower-top mass and long moment arm. This difference between the TLP and the land-based turbine-a more than $60 \%$ increase in DELs - greatly influences the design of this particular tower. A significant increase in tower-base strength is necessary to equal the lifetime of the land-based system. Alternatively, advanced control strategies might achieve load reductions to increase the TLP tower's lifetime.

\subsubsection{Stability Analysis}

Two major instabilities (such as negative damping in at least one mode) were identified. When analyzing DLC 2.1, a platform yaw instability was discovered - the same instability that Jonkman [5] discovered for the barge concept. The instability occurs when the rotor is idling and one blade is seized flat into the wind at a pitch angle of $\theta=0^{\circ}$ and the other two blades are fully feathered at $\theta=90^{\circ}$. This fault event with one seized blade also occurs in DLC 7.1a and results in the same yaw instability as discovered in DLC 2.1. In DLC 7.1a, the TLP is operating in an extreme sea state with extreme winds, as compared to normal wave and winds in DLC 2.1, therefore the yaw instability is more severe in DLC 7.1a. In DLC 7.1a, extreme platform yaw displacements are reached-resulting in extreme loads on the platform and possible knotting of the mooring lines. For those extreme rotational displacements, the limits of the validity of FAST's theory are exceeded significantly, therefore no quantitative values are presented here.

The yaw instability (which is oscillating at the platform yaw natural frequency of $0.0972 \mathrm{~Hz}$ ) is caused by a coupling of the platform yaw with the azimuthal motion of the seized blade. Compared with the barge, the instability is more severe for the TLP. This confirms Jonkman's prediction that the instability would be more pronounced for a TLP design because it is more compliant to platform yaw motions and because smaller moment arms are available [5]. Several methods are suggested for preventing this yaw instability, including installing damping plates, applying the high-speed shaft brake, or reducing the pitch angle of the feathered blades to generate a low persistent torque producing a slow rotor rotation.

HydroDyn does not account for drag from vortex shedding, flow separation, skin friction, and drag from the spokes. The yaw instability therefore most likely will be less severe in reality, because all of these effects can add to more damping of platform yaw. Note that there is the possibility that the vortices generated at the spokes might lead to regions of lower pressure which also could - contrary to the statement above-lead to less damping. Further research on the damping of the platforms therefore is needed, especially regarding the influence of the spokes.

When trying to identify the existence of the tower side-to-side instability in the TLP model in DLC 6.2a (which Jonkman [5] discovered for the land-based turbine), an expanded instability was identified. In design load case $6.2 \mathrm{a}$, the rotor idles and all blades are fully feathered at a pitch angle of $90^{\circ}$ and nacelle yaw misalignments range is $-180^{\circ}<\mathrm{Yaw}<+180^{\circ}$. The turbine in this DLC floats when extreme 50-year wind and wave conditions are present.

It is difficult to analyze the roll/yaw instability in a severe sea state, therefore a simpler test case was created in which the instability could be investigated in isolation and without the disturbing influences of random waves and turbulent winds. The turbine floats in still water with a constant 
wind speed of $50 \mathrm{~m} / \mathrm{s}$, and the nacelle yaw misalignment range is $-180^{\circ}<\mathrm{Yaw}<180^{\circ}$. Figure 5 shows the damping ratios for the 6 platform DOFs at different yaw misalignments.

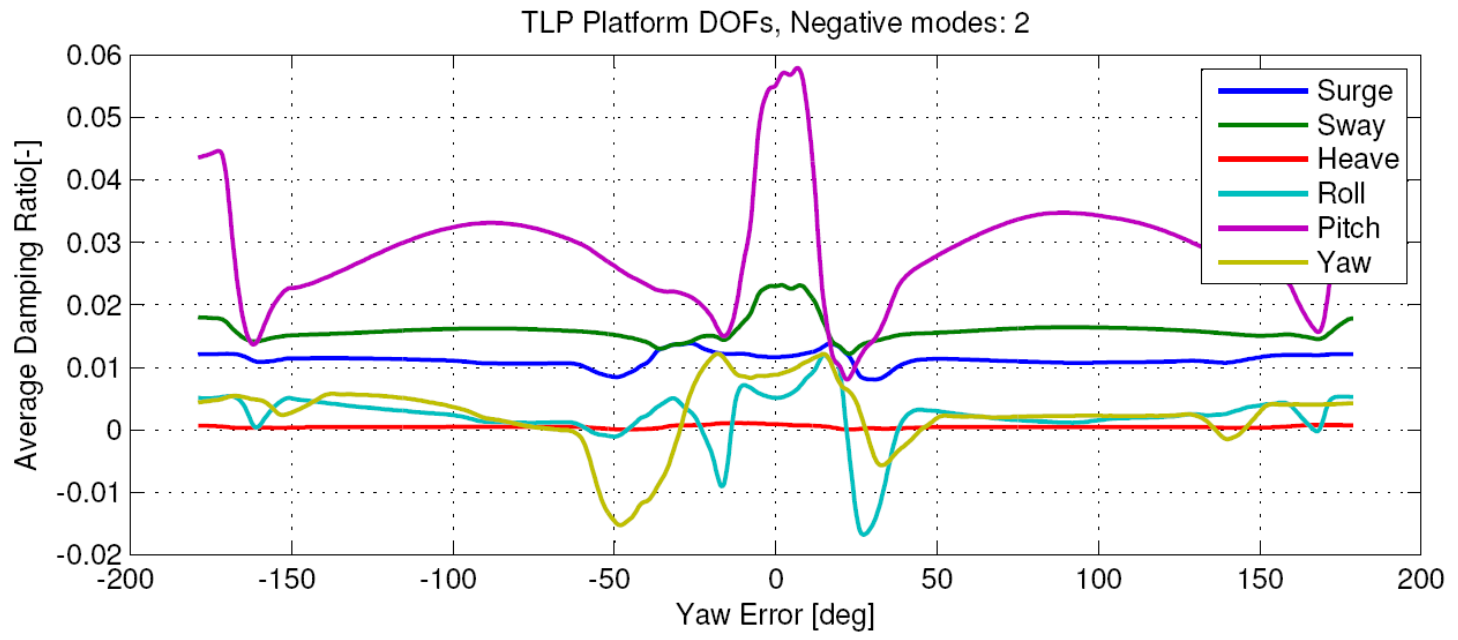

Figure 5. Tension leg platform damping ratios for 6 TLP DOFs at different yaw misalignments

Negative damping in yaw occurs at yaw misalignments between $27^{\circ}<$ Yaw $<46^{\circ},-68^{\circ}<$ Yaw $<$ $-29^{\circ}$, and $135^{\circ}<\mathrm{Yaw}<+145^{\circ}$. In roll, negative damping ratios are found at yaw misalignments of between $-59^{\circ}<\mathrm{Yaw}<-47^{\circ}, 22^{\circ}<\mathrm{Yaw}<38^{\circ}$, and $166^{\circ}<\mathrm{Yaw}<169^{\circ}$. For the remaining DOFs of the model not shown here (see Matha [3]), more negative damping ratios in flap-wise and edgewise blade modes and in tower side-to-side and fore-aft modes were identified.

Further investigation indicated that this instability is caused by a coupling of the blade aerodynamics and the turbine and platform. Interestingly, even simulations using only one DOF (e.g., platform yaw) resulted in negative damping ratios. So far, no final conclusion has been reached regarding an exact explanation of the mechanism causing this instability. Although the exact cause has not been determined, what is known about the instability suggests three possible remedies. First, it might be possible to modify the shape of the airfoils in the blades to reduce the amount of energy absorption at the problematic angles of attack. A second remedy is to apply a fail-safe shaft brake to park the rotor in extreme winds to keep it from reaching the critical azimuth positions. A third option is to allow a slip in the nacelle-yaw drive to keep the rotor from reaching the critical yaw misalignments.

\section{Conclusions}

The study presented here analyzes a 5-MW wind turbine located on a floating offshore TLP using the fully coupled time-domain aero-hydro-servo-elastic design code FAST with AeroDyn and HydroDyn. Significant differences between the higher-fidelity time-domain model and lower-fidelity frequency-domain model have been found and explained. These differences have important implications to the required design process for floating offshore-turbine systems.

An extensive loads and stability analysis for ultimate and fatigue loads was performed using the verified TLP model. Response statistics, ultimate loads, fatigue loads, and instabilities are analyzed and presented in this report. The ultimate loads for the TLP turbine are increased 25\% 
for the tower and over $10 \%$ for the blades. Fatigue DELs are increased $60 \%$ for the tower-base bending moment. The stability analysis identified a severe aerodynamic instability in the platform pitch, platform roll, and tower- and blade-bending modes for a TLP wind turbine that is idling in high winds at certain yaw misalignments with all blades fully feathered at $90^{\circ}$. It also identified a platform yaw instability that occurred when the TLP turbine was idling in high winds with one blade seized at $0^{\circ}$ pitch (and the other two blades at $90^{\circ}$ ).

The model development and analysis process described here can serve as a blueprint for future analysis of new floating-platform concepts. Various designs can be compared to each other using the described analysis process and design tools to reach conclusions on the optimal floatingplatform design. The results of the loads and stability analysis can help resolve fundamental design challenges of the TLP floating system concepts. Yet, the results also indicate that further work on TLP design, controller improvements, and solving instabilities is necessary to develop economically feasible offshore floating wind turbines that can withstand the extreme conditions in the deep offshore environment. More details on this study are presented in the technical report by Matha [3]. Further information on the used hydrodynamic design tool HydroDyn is found in the report by Jonkman [5].

\section{References}

1. Jonkman, J.; Butterfield, S.; Musial, W.; Scott, G. Definition of a 5-MW Reference Wind Turbine for Offshore System Development. NREL/TP-500-38060. Golden, CO: National Renewable Energy Laboratory, February 2009.

2. Tracy, C. Parametric Design of Floating Wind Turbines. M.S. Thesis. Cambridge, MA: Massachusetts Institute of Technology, 2007.

3. Matha, D. Model Development and Loads Analysis of an Offshore Wind Turbine on a Tension Leg Platform, with a Comparison to Other Floating Turbine Concepts. NREL/TP-500-45891. Golden, CO: National Renewable Energy Laboratory, 2009.

4. Larsen, T.J.; Hanson, T.D. "A Method to Avoid Negative Damped Low Frequent Tower Vibrations for a Floating, Pitch Controlled Wind Turbine.” Journal of Physics: Conference Series, The Second Conference on the Science of Making Torque from Wind, Copenhagen, Denmark, 28-31 August 2007 [online journal], 012073, Vol. 75, 2007, URL: http://www.iop.org/EJ/article/1742-6596/75/1/012073/jpconf7 75 012073.pdf?request-

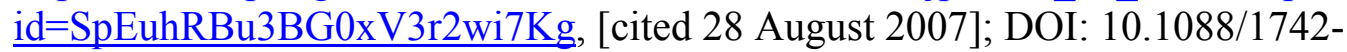
6596/75/1/012073.

5. Jonkman, J. Dynamics Modeling and Loads Analysis of an Offshore Floating Wind Turbine. NREL/TP-500-41958. Golden, CO: National Renewable Energy Laboratory, 2007.

6. Lee, C.H.; Newman, J.N. WAMIT User Manual, Versions 6.3, 6.3PC, 6.3S, 6.3S-PC. Chestnut Hill, MA: WAMIT Inc., 2006.

7. Jonkman, J.; Buhl, M. FAST User's Guide. NREL/TP-500-38230. Golden, CO: National Renewable Energy Laboratory, 2005. 
8. Buhl, M. MCrunch User's Guide. NREL/TP-500-43139. Golden, CO: National Renewable Energy Laboratory, 2008.

9. International Electrotechnical Commission. IEC 61400-3. Wind Turbines-Part 3: Design Requirements for Offshore Wind Turbines. Geneva, Switzerland: International Electrotechnical Commission, 2009. 




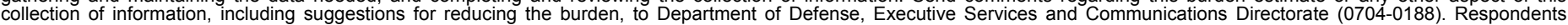

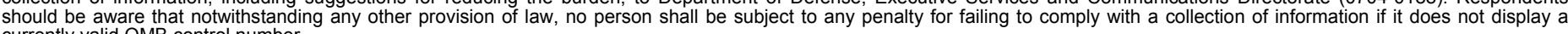

PLEASE DO NOT RETURN YOUR FORM TO THE ABOVE ORGANIZATION.

\begin{tabular}{l|l|ll} 
1. & $\begin{array}{l}\text { REPORT DATE }(D D-M M-Y Y Y Y) \\
\text { February } 2010\end{array}$ & $\begin{array}{l}\text { 2. } \\
\text { REPORT TYPE } \\
\text { Conference Paper }\end{array}$ & 3. DATES COVERED (FrOm - To)
\end{tabular}

4. TITLE AND SUBTITLE

Model Development and Loads Analysis of a Wind Turbine on a

Floating Offshore Tension Leg Platform

5a. CONTRACT NUMBER

DE-AC36-08-GO28308

5b. GRANT NUMBER

5c. PROGRAM ELEMENT NUMBER

6. AUTHOR(S)

Denis Matha, Tim Fisher, Martin Kuhn, and Jason Jonkman

5d. PROJECT NUMBER

NREL/CP-500-46725

5e. TASK NUMBER

WE101211

5f. WORK UNIT NUMBER
7. PERFORMING ORGANIZATION NAME(S) AND ADDRESS(ES)

National Renewable Energy Laboratory

1617 Cole Blvd.

Golden, CO 80401-3393

9. SPONSORING/MONITORING AGENCY NAME(S) AND ADDRESS(ES)
8. PERFORMING ORGANIZATION

REPORT NUMBER

NREL/CP-500-46725

10. SPONSOR/MONITOR'S ACRONYM(S)

NREL

11. SPONSORING/MONITORING AGENCY REPORT NUMBER

12. DISTRIBUTION AVAILABILITY STATEMENT

National Technical Information Service

U.S. Department of Commerce

5285 Port Royal Road

Springfield, VA 22161

\section{SUPPLEMENTARY NOTES}

14. ABSTRACT (Maximum 200 Words)

This report presents results of the analysis of a 5-MW wind turbine located on a floating offshore tension leg platform (TLP) that was conducted using the fully coupled time-domain aero-hydro-servo-elastic design code FAST with AeroDyn and HydroDyn. Models in this code are of greater fidelity than most of the models that have been used to analyze floating turbines in the past—which have neglected important hydrodynamic and mooring system effects. The report provides a description of the development process of a TLP model, which is a modified version of a Massachusetts Institute of Technology design derived from a parametric linear frequency-domain optimization process. An extensive loads and stability analysis for ultimate and fatigue loads according to the procedure of the International Electrotechnical Commission offshore wind turbine design standard was performed with the verified TLP model. Response statistics, extreme event tables, fatigue lifetimes, and selected time histories of design-driving extreme events are analyzed and presented. Loads for the wind turbine on the TLP are compared to those of an equivalent land-based turbine in terms of load ratios. Major instabilities for the TLP are identified and described.

15. SUBJECT TERMS

wind turbine floating platform; model development; loads analysis; tension leg platform

\begin{tabular}{|c|c|c|c|c|}
\hline \multicolumn{3}{|c|}{ 16. SECURITY CLASSIFICATION OF: } & \multirow{2}{*}{$\begin{array}{l}\text { 17. LIMITATION } \\
\text { OF ABSTRACT } \\
\text { UL }\end{array}$} & \multirow{2}{*}{$\begin{array}{l}\text { 18. NUMBER } \\
\text { OF PAGES }\end{array}$} \\
\hline $\begin{array}{l}\text { a. REPORT } \\
\text { Unclassified }\end{array}$ & $\begin{array}{l}\text { b. ABSTRACT } \\
\text { Unclassified }\end{array}$ & $\begin{array}{l}\text { c. THIS PAGE } \\
\text { Unclassified }\end{array}$ & & \\
\hline
\end{tabular}

19a. NAME OF RESPONSIBLE PERSON

19b. TELEPHONE NUMBER (Include area code) 